\title{
OMI and MODIS observations of the anomalous 2008-2009 Southern Hemisphere biomass burning seasons
}

\author{
O. Torres ${ }^{1}$, Z. Chen ${ }^{1}$, H. Jethva ${ }^{1}$, C. Ahn ${ }^{2}$, S. R. Freitas ${ }^{3}$, and P. K. Bhartia ${ }^{4}$ \\ ${ }^{1}$ Dept. of Atmospheric and Planetary Sciences, Hampton University, Hampton, Virginia, USA \\ ${ }^{2}$ Science Systems and Applications Inc., Lanham, Maryland, USA \\ ${ }^{3}$ Center for Weather Forecasting and Climate Studies, INPE, Cachoeira Paulista, Brazil \\ ${ }^{4}$ NASA Goddard Space Flight Center, Greenbelt, Maryland, USA
}

Received: 4 June 2009 - Published in Atmos. Chem. Phys. Discuss.: 13 October 2009

Revised: 17 March 2010 - Accepted: 18 March 2010 - Published: 16 April 2010

\begin{abstract}
Significant inter-annual variability of biomass burning was observed in South America over the 2007-2009 period. The 2007 number of fires detected from space in South America, as well as the magnitude of the atmospheric aerosol load resulting from fire activity, was the largest over the last ten years. The huge 2007 increase in fire activity was followed by large reductions in the 2008 and 2009 burning seasons. Large drops of the atmospheric load of carbonaceous aerosols over the subcontinent, relative to previous years, was registered in 2008 and 2009 by the OMI sensor onboard the Aura platform, and the MODIS sensors on the Terra and Aqua satellites. The 2009 fire season in South America was the least active of the last ten years. Satellite observations of fire statistics, precipitation, and aerosol optical depth data were used to analyze the fire season over South America and Central Africa during the last ten years to understand the factors that led to the 2007 and 2009 extremes. An analysis of precipitation anomaly data shows that the largest 6-month (May-October) precipitation deficit of the last ten years in South America occurred during 2007. The same analysis indicates that in 2009 , this region experienced the largest excess precipitation of the decade. Since precipitation is the most important meteorological factor controlling biomass burning activity, it can be concluded that the 2007 maximum and 2009 minimum in fire activity and aerosol load were driven by the observed levels of precipitation. Analysis of the precipitation record, however, does not explain the extremely low 2008 biomass burning activity. Although the 2008 precipitation deficit was similar in magnitude to the one that in 2005 contributed to the second
\end{abstract}

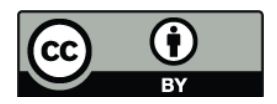

Correspondence to: O. Torres (omar.torres@hamptonu.edu) most intense biomass burning season in the last ten years, the 2008 fire season was surprisingly weak. The combined analysis of satellite data on atmospheric aerosol load, fire counts and precipitation strongly suggests that the observed 2008 decline in aerosol load and fire activity in South America was heavily influenced by conditions other than meteorological factors.

\section{Introduction}

Biomass burning is a widespread agricultural practice for land clearing used in most tropical farmlands in South America (SA) and Central and Southern Africa (CA). It is by far the main source of anthropogenic aerosols in the Southern Hemisphere (SH). In addition to the well known climate implications of biomass burning (Hobbs et al., 1997; Malhi et al., 2008) it also has a direct effect on air quality through the emission of large amounts of particulate matter and chemical byproducts such as $\mathrm{CO}_{2}, \mathrm{~N}_{2} \mathrm{O}, \mathrm{CH}_{4}$, ozone precursors such as $\mathrm{CO}, \mathrm{NO}, \mathrm{NO}_{2}$, and other substances (Jacob et al., 1996). A close examination of the connection between fire variability and climate controls in the tropics is given by van der Werf et al. (2007). For detailed discussion on the role of biomass burning in the deforestation process of the Amazon and other tropical and sub-tropical areas the reader is referred to recently published articles on the subject (Laurance, 2007; Malhi, et al., 2008; Schroeder et al., 2009).

The bulk of biomass burning activities in SA are carried out in a geographical region between $10^{\circ} \mathrm{S}$ and $30^{\circ} \mathrm{S}$ most of which is in Brazil, but also includes Eastern Bolivia, Northwest Paraguay and Northern Argentina. Although biomass burning also takes place in Equatorial Brazil during $\mathrm{SH}$

Published by Copernicus Publications on behalf of the European Geosciences Union. 
summer, most of the SA biomass burning occurs south of $10^{\circ} \mathrm{S}$ during the August-October period with peak activity in September. The CA burning season starts in June at about $10^{\circ} \mathrm{S}$ and slowly progresses southward. Unlike in SA, peak biomass burning activity is reached generally in August but the season extends through November. Although it has been shown that in some cases biomass burning aerosols remain in the boundary layer over land (Labonne et al., 2007), it is clear that in Central Africa and South America, convective activity associated with the intensive heating produced by the fires triggers the vertical transport of smoke to altitudes between 2 and $6 \mathrm{~km}$ into the free troposphere forming a dense carbonaceous aerosol layer that covers most of the source regions and beyond as the smoke is efficiently transported by the prevailing winds thousands of kilometers away from the source regions into the South Atlantic Ocean as well as the South Indian Ocean forming the so-called rivers of smoke (Freitas et al., 2006).

The intensity and seasonality of the biomass burning activity have been documented by means of satellite observations of the effect on the ground (fire counts) as well as the atmospheric effects by means of the qualitative Aerosol Index from near-UV observations and estimates of the actual aerosol load in terms of optical depth from MODIS (MODerate Resolution Imaging Spectro-radiometer) and OMI (Ozone Monitoring Instrument) observations. SA biomass burning shows a great deal of inter-annual variability as shown by the long-term TOMS (Total Ozone Mapping Spectrometer) Aerosol Index record for the period 19791993 (Gleason et al., 1998). Koren et al. (2007, 2009) examined the inter-annual variability of biomass burning in the Amazon basin using MODIS aerosol optical depth data and fire counts observations from the NOAA-12 Advanced Very High Resolution Radiometer (AVHRR) in the period 20002006. They reported a generally increasing trend up to about 2005 followed by a sudden drop in 2006. It was argued that the observed 2006 decline was associated with the implementation of a tri-national biomass burning preventing policy involving the governments of Brazil, Bolivia, and Peru. Schroeder et al. (2009) questioned the validity of the Koren et al. (2007) analysis pointing to potential problems with the AVHRR fire counts data. Biomass burning inter-annual variability has also been documented in terms of satellite measurements of atmospheric column CO (Gloudemans et al., 2009).

In this paper we examine satellite data for the period 2000-2009 from different platforms and sensors to analyze the anomalous 2008 and 2009 SH biomass burning seasons that exhibited significant reduction in fire activity and atmospheric aerosol load in SA in relation to the historical record. The effect of the reduced 2008 fire activity in South America on tropospheric ozone production is analyzed by Ziemke et al., (2009).

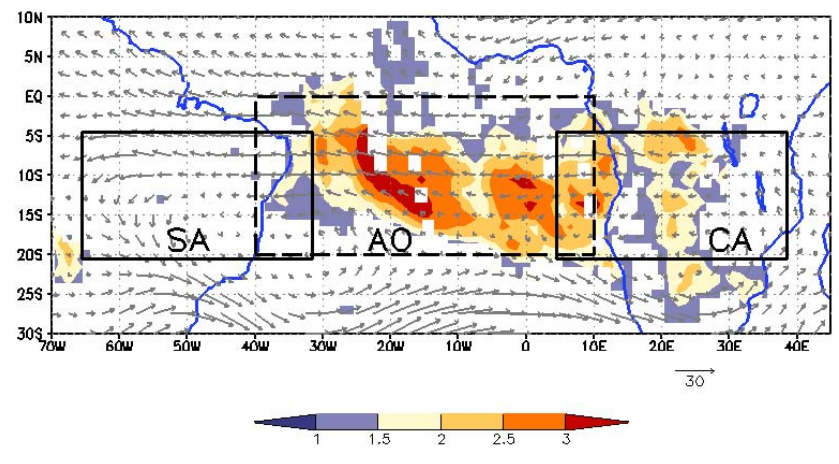

Fig. 1. Spatial distribution of the OMI Aerosol Index on 7 September 2008. Arrows indicate the prevailing NCEP $700 \mathrm{hPa}$ wind field. Boxes indicate regions of analysis in South America (SA), Central Africa (CA), and Atlantic Ocean (AO).

\section{Observations}

In this work we use observations over the period 2000-2009 from sensors on three different satellites. We analyze the spatial and temporal variability of the SH smoke plume using OMI observations in terms of the UV Aerosol Index (UVAI) and the retrieved $388 \mathrm{~nm}$ Aerosol Absorption Optical Depth, AAOD (Torres et al., 2007). Although we rely on the OMI AAOD to uniquely identify the absorbing carbonaceous aerosols resulting from the biomass burning activity without the interference of aerosols from other sources, we also make use of the MODIS aerosol optical depth (AOD) product (Levy et al., 2007) as additional corroboration of the satellite detected aerosols. The fire-counts data set derived from Aqua-MODIS observations (Giglio et al., 2006) is used to monitor the actual fire activity in terms of number of fires per unit area. The third satellite data set used in this analysis is precipitation data as reported by the Tropical Rainfall Measuring Mission (TRMM, Kummerow et al., 2000). In addition to the satellite data we also make use of NCEP (National Centers for Environmental Prediction) reanalysis data (Kalnay et al., 1996) to examine the possible role of the variability of the wind fields on the observed transport patterns.

An analysis of OMI observations indicates that the 2008 and 2009 SH biomass burning seasons were particularly different than in previous years. Figure 1 that shows the spread of SH smoke layer in terms of the OMI Aerosol Index on 7 September 2008 clearly illustrates two features that make the 2008 SH biomass burning season stand out. The figure shows the large horizontal extent of the aerosol plume over the Atlantic Ocean which results from the westward smoke transport all the way from Africa to the shores of Brazil and even reaching the sub-continent. Also shown are the NCEP wind fields at $700 \mathrm{hPa}$. Monthly UVAI average maps (not shown) indicate that the Southern Atlantic oceanic region covered by the smoke plume in 2008 is significantly larger 


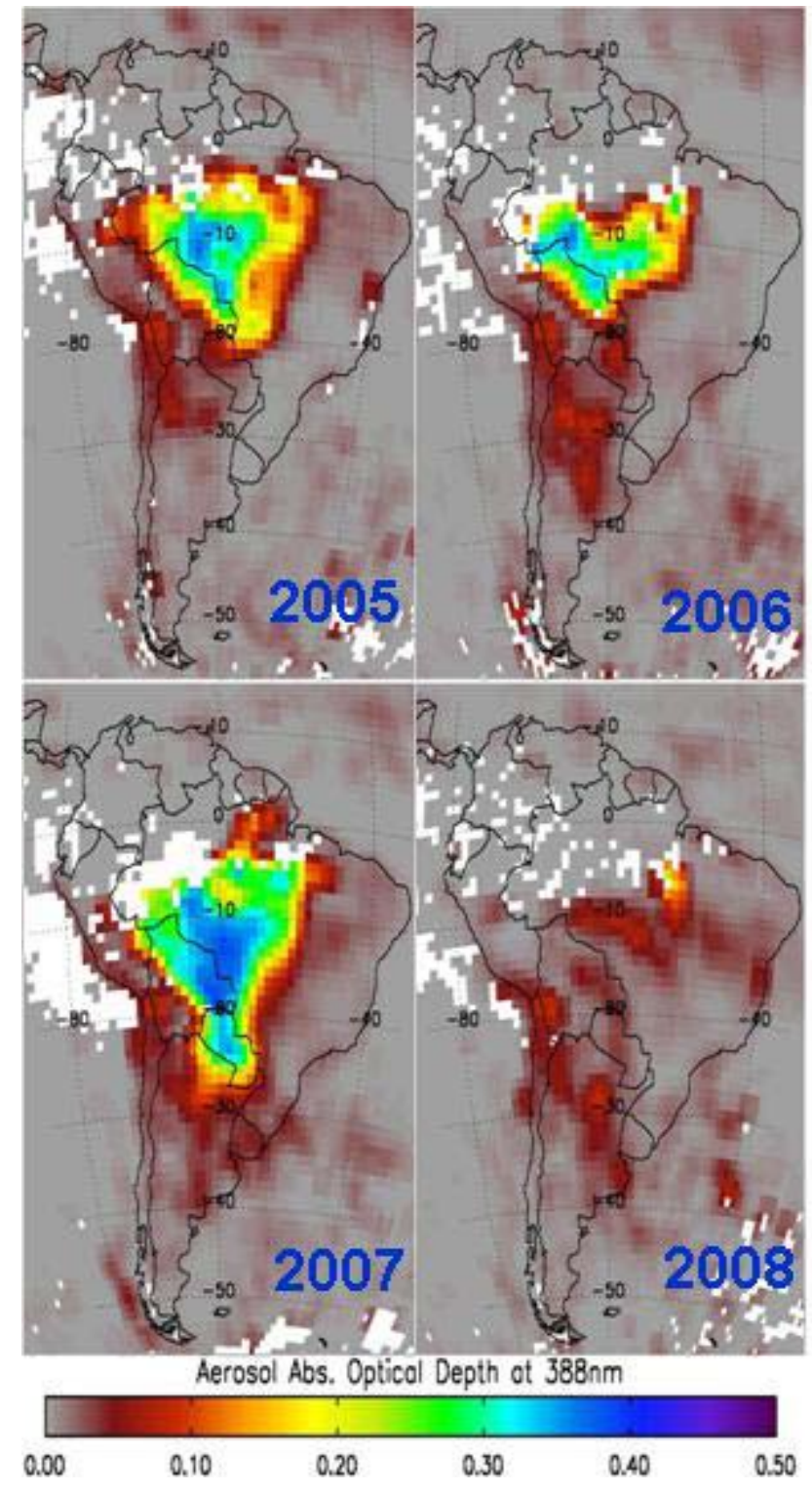

Fig. 2. September average spatial distribution of the South American smoke layer in terms of OMI aerosol absorption optical depth for the 2005-2008 period. White areas indicate regions of persistent cloudiness.

than in any previous years indicating either a more intense than usual African biomass burning or a more efficient transport, or both. The other relevant feature is the spatial extent of the SA smoke layer that in 2008 and 2009 is significantly smaller than what was observed in any of the three previous years of the OMI and MODIS records. This is illustrated on the September average maps of OMI derived aerosol absorption optical depth in Fig. 2.

It is well established that the UVAI is strongly correlated to the atmospheric aerosol load of UV-absorbing aerosols (Hsu et al., 1999). Figure 3 depicts the long term UVAI record averaged over the geographical areas indicated in Fig. 1 for the
South American (SA, $5^{\circ} \mathrm{S}-20^{\circ} \mathrm{S}, 65^{\circ} \mathrm{W}-30^{\circ} \mathrm{W}$ ) and Central African $\left(\mathrm{CA}, 5^{\circ} \mathrm{S}-20^{\circ} \mathrm{S}, 5^{\circ} \mathrm{E}-38^{\circ} \mathrm{E}\right)$ regions. Data shown includes observations from the Nimbus7 (1979-1992) and Earth Probe (1996-2001) TOMS sensors and the Aura-OMI instrument (2005-2009). No reliable AI data is available for the periods 1993-1995 and 2002-2004. The long term CA UVAI record shows a repeatable annual cycle with clearly defined maxima generally in August. The SA record on the other hand, exhibits a very large inter-annual variability. Although maxima UVAI values are regularly observed in September, on several years hardly any biomass burning seemed to have taken place. Years of minimum biomass burning activity according to the UVAI record are 1982, 1989, 2000, 2001, 2006, 2008 and 2009. In terms of the UVAI the 2008 and 2009 SA biomass burning seasons are the least active since the beginning of the OMI record in October 2004, and among the least active seasons in the combined 24 year record from Nimbus7-TOMS, Earth Probe-TOMS and Aura-OMI observations. The September average MODIS AOD in 2008 and 2009 are two lowest for the SA region since 2001 (see Table 1 and related discussion). Duncan et al., (2003) have previously documented the pronounced difference in the inter-annual variability of biomass burning between the SA and CA regions. The clear contrast between the inter-annual variability of these regions suggests that the combination of natural and anthropogenic factors operates in different ways in these two geographical areas. In this paper we examine the possible causes of the observed 2008-2009 South American biomass burning season in an effort not only to understand the driving factors of the fire activity in these specific years but also to shed light on the possible reasons of the long-term variability of biomass burning in SA that is characterized by the occurrence of years of minimum activity in contrast to the regularity of the biomass burning activities in Central Africa.

\section{Data analysis}

Monthly average values of OMI AAOD and fire counts derived from satellite observations at a $1^{\circ} \times 1^{\circ}$ resolution were calculated over the SA and CA regions shown in Fig. 1 for the 2005-2009 five year period. We also use TRMM derived data on precipitation amounts at a $5^{\circ} \times 5^{\circ}$ resolution for the 2000-2009 period. The availability of the MODIS AOD record over the same period as the precipitation observations was instrumental in the analysis presented in this section, where a brief description of the observed multi-year record of these parameters is presented.

\subsection{Fire counts and aerosol statistics}

Figure 4 shows the time series of parameters closely related to the intensity and frequency of biomass burning in South America and Central Africa. The top panel shows the 


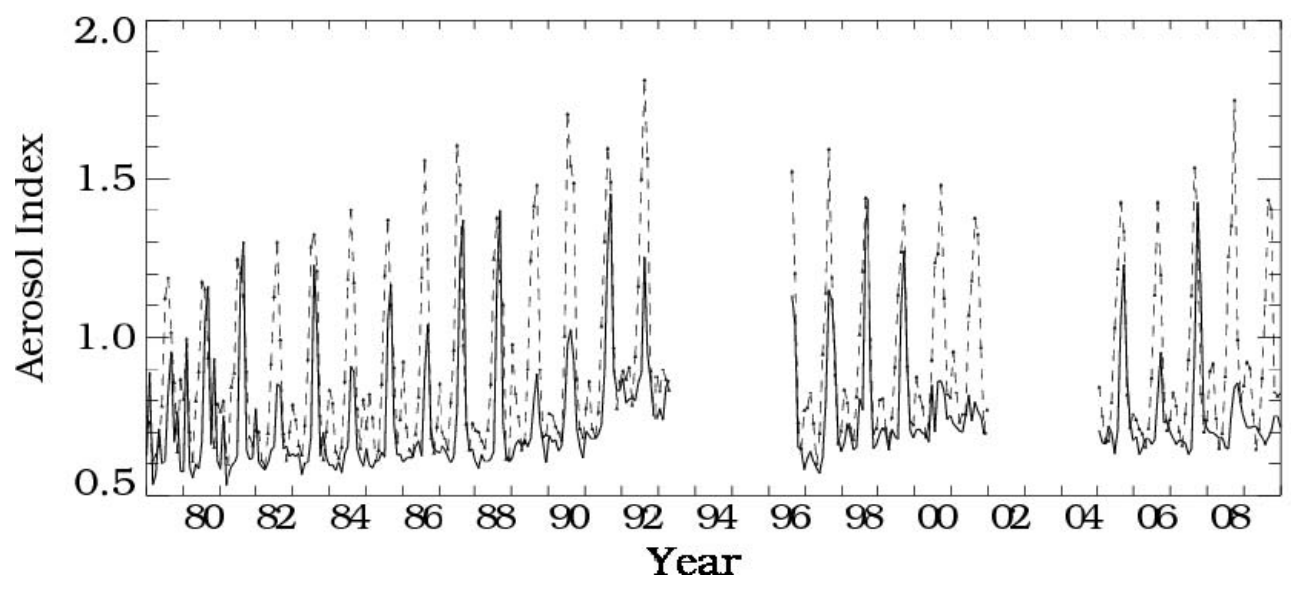

Fig. 3. Long term record of Aerosol Index over South America (solid line) and Central Africa (dashed line). See text for details.
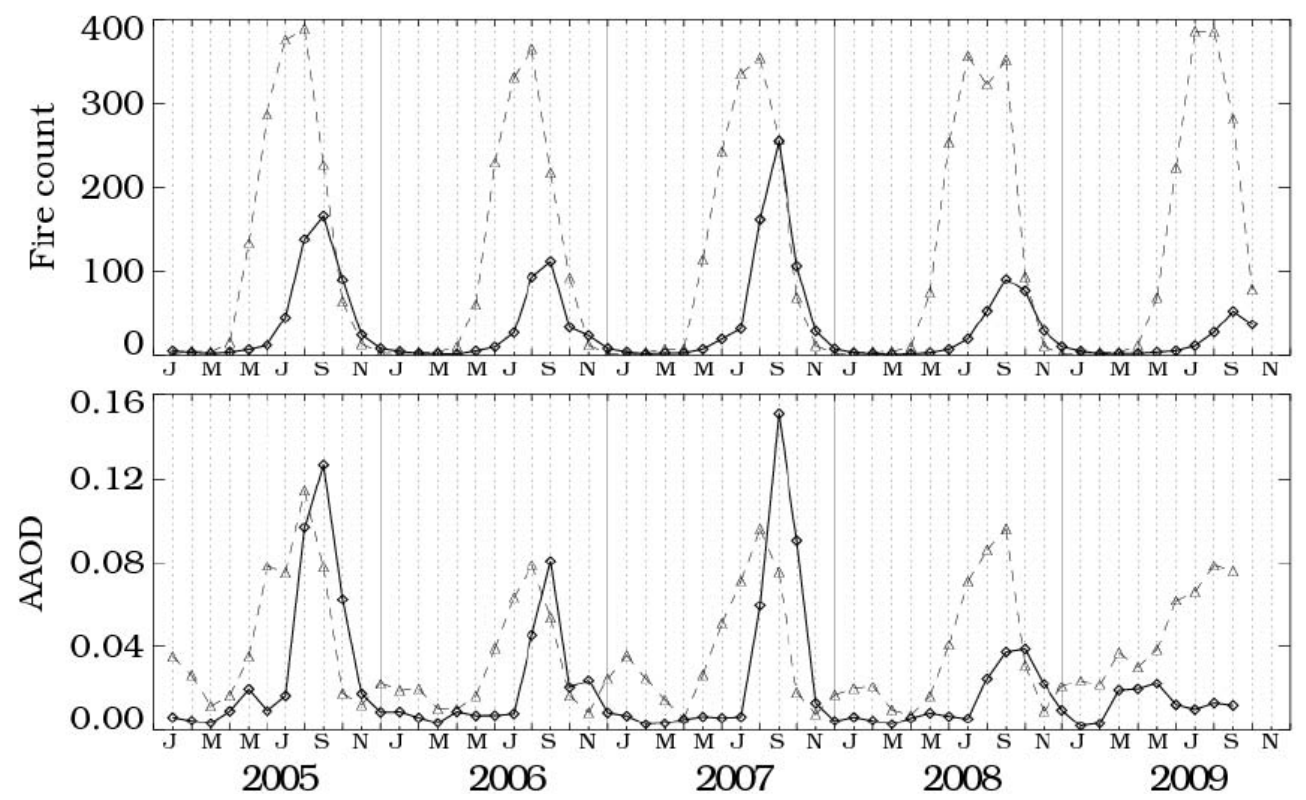

Fig. 4. Five year record of monthly average values of fire counts (top), and $388 \mathrm{~nm}$ aerosol absorption optical depth (bottom) for the SA (solid line) and CA (dashed line) regions.

number of fires per-pixel detected by the Aqua-MODIS sensor over the regions of the analysis. A significant inter-annual variability can be observed over South America (solid line). In 2005 the maximum number of fires per pixel was about 180, went down to about 130 in 2006 and peaked at 250 in 2007, the largest of the Aqua-MODIS record. The 2008 value did not reach 100 fires per pixel while the 2009 value was even lower reaching only about 40 , the lowest of the Aqua-MODIS record. Unlike the large inter-annual variability found in South America, the time series of the fire count data exhibits a very repetitive and steady annual cycle over the Central African region (dashed line). The peak number of fires remains remarkably constant at about 400 over the fouryear period. The bottom panel of Fig. 4 shows the tempo- ral evolution of the OMI derived Aerosol Absorption Optical Depth. The AAOD over the South American region exhibits identical inter-annual variability as the number of fires with a maximum value in 2007, and minima in 2008 and 2009. Peak monthly values of $0.13,0.08,0.15,0.04$ and less than 0.02 are observed in September in the five years of the analysis. In Central Africa, peak monthly AAOD values between 0.08 and 0.12 take place in August. The 2008 data shows a onemonth lag in the month of peak AAOD in both regions with peaks in September and October for CA and SA respectively a month later than in the previous three years. In addition, the clearly defined SA September peak in the previous three years is absent in 2008 when August and September show similar average AAOD values. The observed inter-annual 


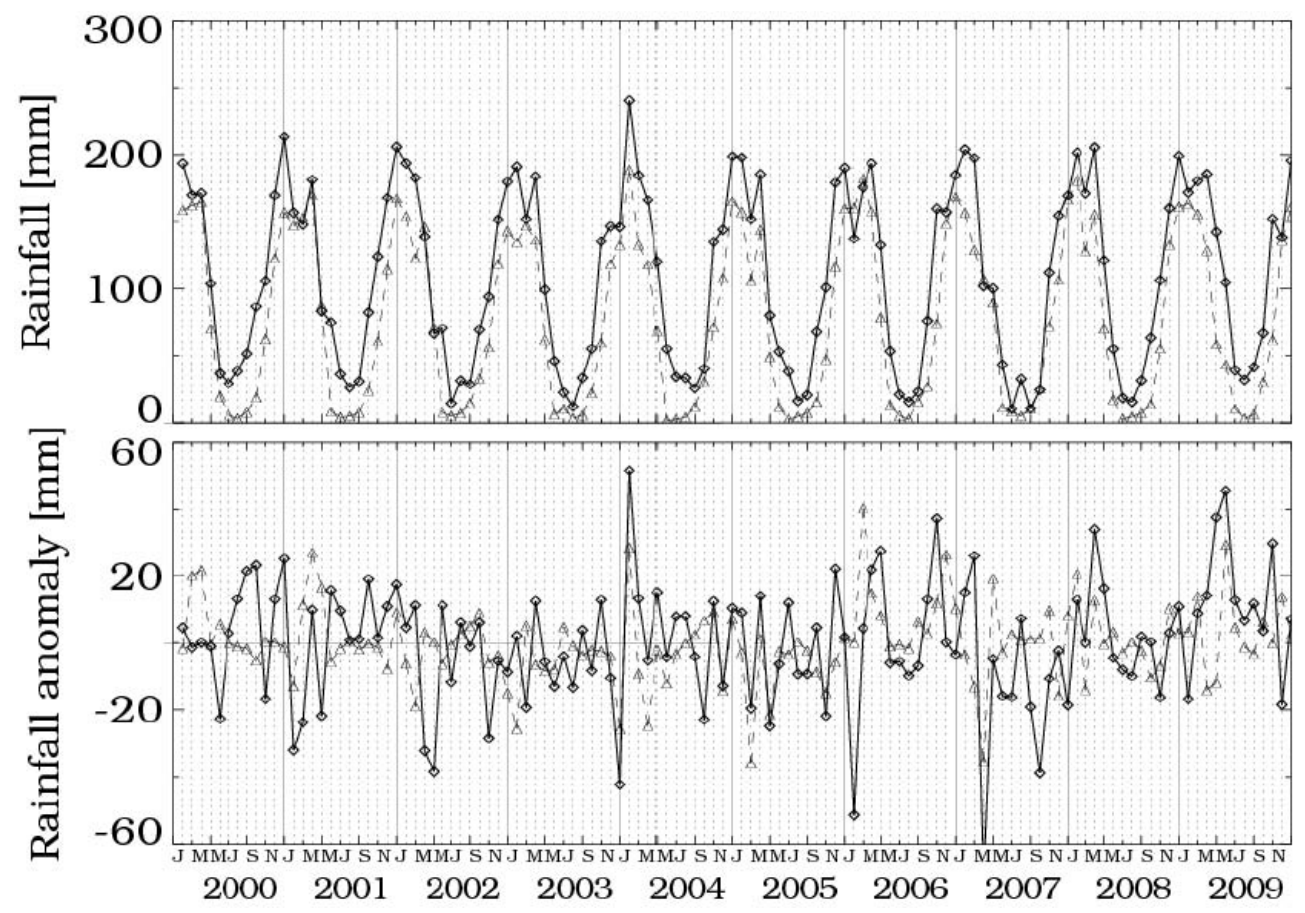

Fig. 5. Rainfall amount (top), and rainfall anomaly (bottom) for SA (solid line) and CA (dashed line) for the period 2000-2009. See text for details.

variability of the OMI-derived AAOD over the SA region is consistent with the similarly calculated regional average of the Aqua-MODIS $550 \mathrm{~nm}$ aerosol optical depth (not shown). Both the MODIS AOD and the OMI AAOD show a reduction of over a factor of three from 2007 to 2008. The 2007-2008 decrease in the number of fires was $62 \%$ whereas the AAOD value decreased by $73 \%$. The consistency of the inter-annual variability of independently derived parameters confirms that the observed 2007-2008 large decrease on fire activity is real and not the effect of possible instrumental degradations affecting the satellite derived quantities.

\subsection{Precipitation analysis}

To gain an understanding of the influence of the regional meteorology on the fire activity we examine the ten-year record (2000-2009) of precipitation over the regions of the study using TRMM data as shown on the top panel of Fig. 5.The decadal precipitation record is used to produce a climatological annual cycle to be used in the calculation of a rainfall anomaly data set. As expected the annual cycle for the two regions shows many similarities. The dry season in Central Africa is much longer than the one in South America. This explains the longer CA biomass burning season that starts about two months earlier and lasts almost twice as long as the three-month long SA burning season. To highlight the annual variability we have also plotted in the bottom panel of Fig. 5 the resulting precipitation anomaly in the SA and CA regions after subtracting the 2000-2009 mean annual cycle.
An anomalous increase in precipitation in the months previous to the onset of or during the burning season in SA could have produced a higher level of fuel moisture and, therefore, a reduction in the overall spatial coverage of fire ignition and intensity could be expected (Uhl et al., 1988). In addition, increased wet deposition resulting from enhanced precipitation would shorten the lifetime of the atmospheric aerosol load and its downwind transport (Freitas et al., 2005). By the same token, intensification of the fire activity and increased aerosol load could also be expected if unusually dry conditions had prevailed. A close examination of the observed rainfall anomalies during the May-October period (which includes three months previous to burning season plus the actual months when the burning takes place) reveals the expected precipitation-fire activity relationship that explains some of the observed inter-annual variability in South America. Table 1 lists the satellite measured ten-year record of 6-month precipitation anomaly (column 2) and the monthly and spatially averaged MODIS aerosol optical depth for the month of peak aerosol load (column 3) for the SA region. The same quantities for the CA region are shown in column 4 and 5. Larger anomalies and a higher annual variability take place in the SA region. Year 2009 shows the largest positive anomaly in both the SA and CA regions over the last ten years, although the SA region value is about three times as large as in CA. On the other hand, year 2007 is by far the driest in SA while 2005 shows the largest precipitation decrease in CA. A rainfall deficit of $30 \mathrm{~mm}(-9 \%)$ was registered in 


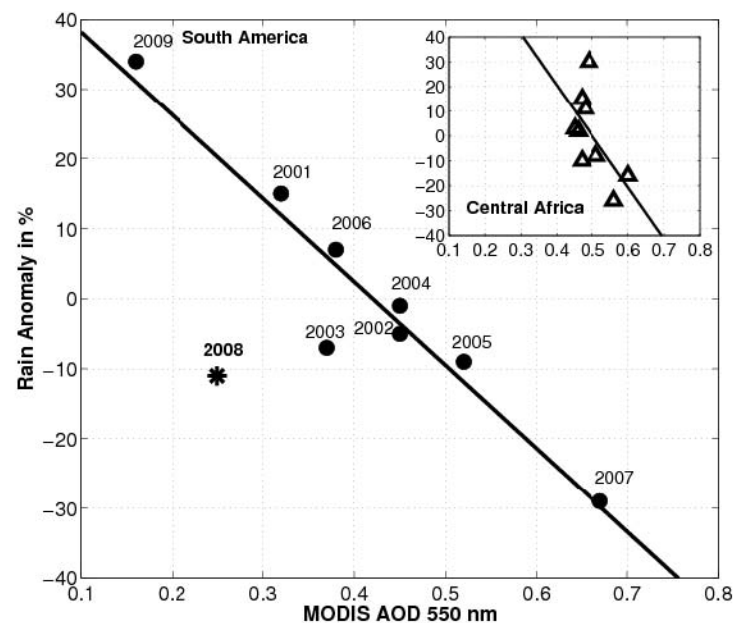

Fig. 6. Observed relationship between rainfall anomaly and atmospheric aerosol load.

2005 whereas a precipitation increase of about $22 \mathrm{~mm}$ (7\%) over the six-month period is apparent in 2006. Although the 2006 increase in precipitation is small as an average for the large area in this study, it is qualitatively consistent with the reduced level of 2006 fire activity and aerosol load relative to the previous year. As reported by Schroeder et al. (2009), the region affected by the 2006 positive rainfall anomaly included regions of Mato Grosso and Pará in Eastern Brazil that accounts for most of the Amazonian fire activity. The severe 2007 drought in SA with a six-month precipitation deficit of $93 \mathrm{~mm}(28 \%)$ may also explain the high incidence of 2007 fire activity which is also the highest in terms of fire counts and aerosol load as shown in Figure 4 and column 3 of Table 1 . The 2008 anomaly of $-36 \mathrm{~mm}(-11 \%)$ is similar in magnitude to the $-9 \%$ registered in 2005 . Yet, during 2008 a very large reduction in both fire activity and atmospheric aerosol load is clearly observed in SA, in contrast to the very active 2005 season. Note that in year 2005 a precipitation anomaly of similar magnitude associated with measurements of large aerosol concentration was observed on both the SA and $\mathrm{CA}$ regions. A similar situation (i.e., high precipitation deficit in both areas) takes place in 2008 but this time the aerosol load in SA is significantly reduced whereas the CA spatially averaged aerosol load is the largest in the MODIS record. The wettest of the ten-year period in SA is 2009 with an excess 6-month precipitation of $110 \mathrm{~mm}(34 \%)$, and, as expected, the lowest recorded levels of both fire activity and aerosol load.

Except for year 2008, the observed variability in biomass burning in SA (in terms of both fire activity and aerosol load) in the 2000-2009 period is well correlated with the observed variability in precipitation as depicted in Fig. 6. The scatter plot in Fig. 6 illustrates the observed relationship between the spatially averaged MODIS aerosol optical depth over the SA region on the month of peak aerosol concentration (generally
Table 1. May-October Accumulative Rainfall Anomaly (mm) for the 2000-2009 period and September average aerosol optical depth over the study areas.

\begin{tabular}{lclcl}
\hline \multirow{2}{*}{ Year } & \multicolumn{2}{c}{ South America } & \multicolumn{2}{c}{ Central Africa } \\
& Anomaly (mm) & MODIS AOD & Anomaly (mm) & MODIS AOD \\
\hline 2000 & 22 & n/a & -2 & n/a \\
2001 & 48 & 0.32 & -10 & 0.51 \\
2002 & -18 & 0.45 & 4 & 0.45 \\
2003 & -22 & 0.37 & -12 & 0.47 \\
2004 & -3 & 0.45 & 3 & 0.46 \\
2005 & -30 & 0.52 & -31 & 0.56 \\
2006 & 22 & 0.38 & 18 & 0.47 \\
2007 & -93 & 0.67 & 13 & 0.48 \\
2008 & -36 & 0.25 & -19 & 0.60 \\
2009 & 110 & 0.18 & 36 & 0.49 \\
\hline
\end{tabular}

September) and the accumulated 6-month rainfall anomaly for the nine continuous years of available MODIS aerosol data. The spatially averaged MODIS aerosol optical depth on 8 of the 9 -year period in the analysis increases monotonically with decreasing rainfall anomaly. The resulting linear fit, calculated using all years but 2008, shows that precipitation anomaly and aerosol load are clearly anti-correlated yielding a correlation coefficient of 0.91 . Qualitatively similar relationships exist between precipitation anomaly and the fire counts data. The 2008 season stands out for the significantly reduced atmospheric aerosol load (and number of fires) in spite of the occurrence of dry conditions similar to 2005. A similar plot for the CA region, shown in the inset of Fig. 6, indicates that fire activity in CA is not as closely related to precipitation fluctuations as it is in SA. The correlation coefficient for the CA fit is 0.60 . The clear 2008 departure from the observed aerosol load-precipitation relationship in SA suggests that additional factors may have been involved in the suppression of fires observed during the 2008 biomass burning season. The low level of fire activity may have been the result of economic or regulatory measures that somehow prevented in 2008 the traditionally high level of biomass burning in August and September. The two-panel Fig. 7 shows a comparison on a regional basis of the TRMM observed 2008 rainfall anomaly (6-month total) and Aqua-MODIS detected fire reduction (in relation to 2007) in South America during September. The fire difference map (on the right) shows that most of the decrease in 2008 fire activity took place in the Brazilian states of Mato Grosso, Tocantis, Bahia, Piauí, and Maranhão. The rainfall anomaly distribution (left map) shows that overall a precipitation deficit prevailed over most of this large region, that should have contributed to increased fire activity. A small precipitation increase took place in a region south east of Pará state, north of Mato Grosso, where high fire incidence was observed in 2007. A region in northern Bolivia affected by the 2008 drought shows increased fire counts relative to 2007 . The total number of fires detected in Brazil in 2008 went down by $62 \%$ with respect to 2007 . On 


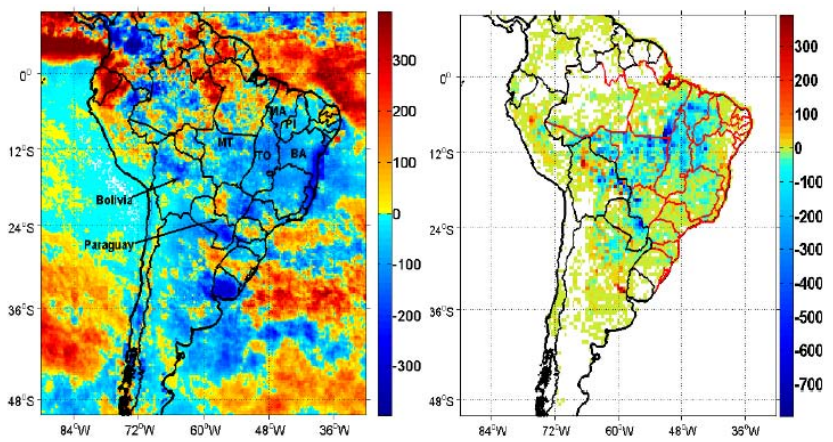

Fig. 7. Regional variability of the 6-month rainfall anomaly (left) and spatial distribution of the observed 2008 decrease in the number of September fires in relation to 2007 (right). See text for details.

the other hand, the total number of fires in the rest of South America (including the totality of Bolivia and Paraguay as well as Northern Argentina but excluding Brazil) went down only by $4 \%$ in 2008 . The $2007-2008$ fire reduction following political boundaries suggests that the 2008 decrease in burning observed in South America might have been related to the effect of economic and/or regulatory forces that were in effect primarily in Brazil resulting in a lesser number of fires ignited.

\subsection{Transport}

Satellite observations show that westward transport of carbonaceous aerosols from the sources in Central Africa and across the Atlantic Ocean was particularly efficient in September during the 2008 biomass burning season. Such efficient transport requires abundant particulate matter production at the source areas as well as free troposphere wind speeds high enough to achieve the mobilization of the carbonaceous aerosol layer across large distances over time scales shorter than those of gravitational settling and other removal mechanisms. The September monthly average horizontal extent of the smoke layer over the ocean has been quantified as the fractional area of Southern Atlantic Ocean in the box (see Fig. 1) where the September average UVAI is larger than unity. Table 2 lists the calculated September averages of oceanic extent of the smoke layer; the $700 \mathrm{hPa}$ wind speeds from NCEP re-analysis; the regional average UVAI value in Central Africa over the source areas; and the monthly average $380 \mathrm{~nm}$ aerosol optical depth reported at the Mongu AERONET site (Eck et al., 2001) for the 2005-2008 period. The tabulated data show a clear correlative connection between the oceanic coverage of the aerosol layer, the wind speed and the aerosol production at the source areas. The connection is particularly robust and positive during the last three years. The increasing wind speed as a function of time given by the NCEP reanalysis is somewhat surprising but consistent with previously reported analysis (Pielke et al., 2001).
Table 2. September average ocean coverage, wind speed and aerosol source strength.

\begin{tabular}{lllll}
\hline Year & $\begin{array}{l}\text { Oceanic } \\
\text { Coverage }(\%)\end{array}$ & $\begin{array}{l}700 \mathrm{hPa} \\
\text { wind speed }(\mathrm{m} / \mathrm{s})\end{array}$ & $\begin{array}{l}\text { AI }(\mathrm{CA}) \\
(380 \mathrm{~nm})\end{array}$ & $\begin{array}{l}\text { Mongu } \\
\text { AOD }\end{array}$ \\
\hline 2005 & 54 & 5.5 & 1.3 & - \\
2006 & 33 & 5.5 & 1.2 & 0.82 \\
2007 & 62 & 6.7 & 1.3 & 0.88 \\
2008 & 81 & 7.0 & 1.7 & 0.96 \\
\hline
\end{tabular}

\section{Discussion}

The observed decrease in the OMI signal (on both Aerosol Index and Absorption Optical Depth) and MODIS extinction optical depth in 2008 and 2009 over South America is consistent with the reported fire count statistics that clearly indicate an actual reduction in the number of fires in South America during the burning seasons in 2008 and 2009. An analysis of the link between the precipitation anomalies and the September spatially averaged aerosol load over the period 2001-2009 shows a clear relationship between excess precipitation and reduced fire activity and, conversely, between rainfall deficit and increased fire activity and aerosol production. The precipitation link seems to also adequately explain the 2007 surge in biomass burning activity. Fires are generally used for forest clearing by small farmers and plantation owners who clear understory shrubbery and cut forest trees. When the area has dried after a few months it is burned. Although the fires may be intended to burn only limited areas, they often spread beyond the target agricultural plots and consume pristine rainforest. The situation of unintended forest burning is worst in dry years like 2005 and 2007. Thus, the case can be made that the large number of fires observed in 2007 was propitiated by the precipitation deficit of about $30 \%$ that affected the study area in SA. This in turn led to record levels of atmospheric aerosol load as reported by satellite observations by the OMI and MODIS sensors. The low incidence of fire activity and low aerosol levels in 2006 and 2009 can also be understood as a consequence of the excess rainfall amount that represented precipitation increases of $7 \%$ and $34 \%$ respectively relative to the long-term mean. Thus, the decrease in aerosol load in 2006 attributed by Koren et al. (2007) to implementation of environmental regulations seem to have been associated to a decrease of precipitation as suggested by Schroeder et al (2009) and confirmed by this work. The precipitation connection, however, does not explain the reported low levels of biomass burning in 2008, a year in which a rainfall deficit similar to the one in 2005 took place. Yet, the observed 2008 fire activity is inconsistent with the expected rainfall anomaly-fire activity relationship. The absence of a clear meteorological explanation to the observed 2008 biomass burning anomaly in SA is 
confirmed by the analysis of the biomass burning season in the meteorologically similar region of Central and Southern Africa that shows a climatologically persistent 2008 annual cycle in both the aerosol load as well as fire counts. The partitioning by political boundaries of the actual number of satellite detected fires in SA clearly suggests that the large decrease in biomass burning in 2008 was mainly confined to Brazil probably as a result of factors other than meteorological.

The combined TOMS-OMI long-term UVAI record and MODIS decadal observations of carbonaceous aerosol production in Central Africa and South America highlights the essentially different economical and political nature of the processes that regulate biomass burning activity in the two regions. In Central Africa biomass burning is a longestablished agricultural practice for the disposal of agricultural residues. In South America, on the other hand, biomass burning is used for both the disposal of agricultural waste as well as a way of incorporating new land to economic activities. The analysis presented here strongly suggests that factors other than the natural role of precipitation influenced the 2008 biomass burning season in SA when very low fire activity was observed in spite of experiencing the second most intense precipitation deficit in a decade. Although as discussed by Koren et al. (2007, 2009) government environmental initiatives in South America have begun to be implemented recently, we do not have concrete evidence to support the hypothesis that specific regulations and/or economic forces in place in Brazil were responsible for the anomalously low 2008 biomass burning season. Official Brazilian government figures available on the environmental website http://www.mongabay.com indicate that the rate of deforestation in Brazil went up by $11 \%$ in 2008 . This increase represents a change in a decreasing trend since 2005 . No correlation between deforestation rate and biomass burning activity is observed because land clearing by fire is just one of several deforestation mechanisms that include logging and public works for economic development. Without any way of actually showing a clear cause-effect relationship to link the resulting low levels of fire activity to regulatory or economic forces, we can only speculate on plausible causes such as enforcement of existing regulations on land use, drop in the international price of cash crops that may not stimulate continued cultivation, or changes in the ways of disposing of agricultural residues in light of the need of preserving any harvested wood resulting from logging activities. In light of the overwhelming effect of precipitation in 2007 and 2009 on the magnitude of the measured fire counts and aerosol optical depth, it is difficult to draw any clear conclusion on the temporal evolution of the anthropogenic component associated with the use of fire for land clearing in South America. Although the 2008 season indicates a precipitation unrelated drop in biomass burning activity, continued monitoring and detailed analysis of additional deforestation-related parameters are needed.
The combined effect of large aerosol amounts generated during the African biomass burning season and high free troposphere wind speeds led to the formation of a synoptic scale aerosol layer that blanketed the Southern Atlantic Ocean between $10^{\circ} \mathrm{S}$ and $25^{\circ} \mathrm{S}$. An interesting finding out of this study is the observed variability in free troposphere wind speeds in the region of this study. The NCEP data shown in Table 2 show a steady wind speed increase over the last four years. Given the short length of the data record in the analysis it is not clear if an actual trend is present or the observed tendency is just a manifestation of the variability of the system. A more detailed analysis of this effect and its possible long-term effect on aerosol transport is certainly warranted but it is beyond the scope of this study.

Edited by: I. Aben

\section{References}

Duncan, B. N., R. V. Martin, A. C. Staudt, R. Yevich, and J. A. Logan, Interannual and seasonal variability of biomass burning emissions constrained by satellite observations, J. Geophys. Res., 108(D2), 4100, doi:10.1029/2002JD002378, 2003

Eck, T. F., Holben, B. N., Ward, D. E., Dubovik, O., Reid, J. S., Smirnov, A., Mukelabai, M. M., Hsu, N. C., O’Neill, N. T., and Slutsker, I.: Characterization of the optical properties of biomass burning aerosols in Zambia during the 1997 ZIBBEE field campaign, J. Geophys. Res., 106(D4), 3425-3448, 2001.

Freitas, S. R., Longo, K. M., Siva-Dias, M. A. F., Silva-Dias, P. L., Chatfield, R., Prins, E., Artaxo, P., Grell, G. A., and Recuero, F. S.: Monitoring the transport of biomass burning emissions in South America, Environ. Fluid Mech., 5, 135-167, doi:10.1007/s10652-005-0243-7, 2005.

Freitas, S. R., Longo, K. M., and Andreae, M.: Impact of including the plume rise of vegetation fires in numerical simulations of associated atmospheric pollutants, Geophys. Res. Lett., 33, L17808, doi:10.1029/2006GL026608, 2006.

Giglio, L., Csiszar, I., and Justice, C. O.: Global distribution and seasonality of active fires as observed with the Terra and Aqua Moderate Resolution Imaging Spectroradiometer (MODIS) sensors, J. Geophys. Res., 111, G02016, doi:10.1029/2005JG000142, 2006.

Gleason, J. F., Hsu, N. C., and Torres, O.: Biomass burning smoke measured using ackscattered ultraviolet radiation: SCARB and Brazilian smoke interannual variability, J. Geophys. Res., 103(D24), 31969-31978, 1998

Gloudemans, A. M. S., de Laat, A. T. J., Schrijver, H., Aben, I., Meirink, J. F., and van der Werf, G. R., SCIAMACHY CO over land and oceans: 2003-2007 interannual variability, Atmos. Chem. Phys., 9, 3799-3813, 2009

Hobbs, P. V., Reid, J. S., Kotchenruther, R. A., Ferek, R. J., and Weiss, R.: Direct radiative forcing by smoke from biomass burning, Science, 272, 1776-1778, 1997

Hsu, N., Herman, J., Torres, O., Holben, B., Tanre, D., Eck, T., Smirnov, A., Chatenet, B., and Lavenu, F.: Comparisons of the TOMS aerosol index with Sun-photometer aerosol optical thick- 
ness: Results and applications, J. Geophys. Res., 104(D6), 62696279, 1999.

Jacob, D. J., Heikes, B. G., Fan, S. M., et al.: Origin of ozone and NOx in the tropical troposphere: A photochemical analysis of aircraft observations over the South Atlantic basin, J. Geophys. Res., 101(D19), 24235-24250, 1996.

Kalnay, E., Kanamitsua, M., Kistlera, R., et al.: The NCEP/NCAR 40-year Reanalysis Project, B. Am. Meteorol. Soc., 77, 437-471, 1996.

Koren, I., Remer, L. A., and Longo, K.: Reversal of trend of biomass burning in the Amazon, Geophys. Res. Lett., 34, L20404, doi:10.1029/2007GL031530, 2007.

Koren, I., Remer, L. A., Longo, K., Brown, F., and Lindsey, R.: Reply to comment by W. Schroeder et al. on "Reversal of trend of biomass burning in the Amazon," Geophys. Res. Lett., 36, L03807, doi:10.1029/2008GL036063, 2009.

Kummerow, C., Simpson, J., Thiele, O., et al.: The status of Tropical Rainfall Measuring Mission (TRMM) after two years in orbit, J. Appl. Meteorol., 12, 1965-1982, 2000.

Labonne, M., Breon, F.-M., and Chevallier, F.: Injection height of biomass burning aerosols as seen from a spaceborne lidar, Geophys. Res. Lett., 34, L11806, doi:10.1029/2007GL029311, 2007.

Laurance, W.: Switch to Corn Promotes Amazon Deforestation, Science, 318(5857), 1721, doi:10.1126/science.318.5857.1721b, 2007.

Levy, R. C., Remer, L. A., Mattoo, S., Vermote, E. F., and Kaufman, Y. J.: Second-generation operational algorithm: Retrieval of aerosol properties over land from inversion of Moderate Resolution Imaging Spectroradiometer spectral reflectance, J. Geophys. Res., 112, D13211, doi:10.1029/2006JD007811, 2007.
Malhi, Y., Roberts, J., Betts, R., Killeen, T., Li, W., and Nobre, C, Climate Change, Deforestation, and the Fate of the Amazon. Science, 319 (5860), 169-172. doi:10.1126/science.1146961, 2008.

Pielke Sr., R. A., Chase, T. N., Kittel, T. G. F., Knaff, J. A., and Eastman, J.: Analysis of 200 mbar zonal wind for the period 1958-1997, J. Geophys. Res., 106(D21), 27287-27290, 2001.

Schroeder, W., Giglio, L., and Arave'quia, J. A.: Comment on "Reversal of trend of biomass burning in the Amazon" by Ilan Koren, Lorraine A. Remer, and Karla Longo, Geophys. Res. Lett., 36, L03806, doi:10.1029/2008GL035659, 2009

Torres, O., Tanskanen, A., Veihelmann, B., Ahn, C., Braak, R., Bhartia, P. K., Veefkind, P., and Levelt, P.: Aerosols and surface UV products from Ozone Monitoring Instrument observations: An overview, J. Geophys. Res., 112, D24S47, doi:10.1029/2007JD008809, 2007.

Uhl, C., Kauffman, J. B., and Cummings, D. L.: Fire in the Venezuelan Amazon 2: Environmental conditions necessary for forest fires in the evergreen rainforest of Venezuela, Oikos, 53(2), 176-184, 1988.

van der Werf, G. R., Randerson, J. T., Giglio, L., Gobron, N., and Dolman, A. J.: Climate controls on the variability of fires in the tropics and subtropics, Global Biogeochem. Cy., 22, GB3028, doi:10.1029/2007GB003122, 2007.

Ziemke, J. R., Chandra, S., Duncan, B. N., Schoeberl, M. R., Damon, M. R., Torres, O., and Bhartia, P. K.: Recent biomass burning events in the tropics and elevated concentrations of tropospheric ozone, Geophys. Res. Lett., 36, L15819, doi:10.1029/2009GL039303, 2009. 